\title{
A cross-sectional survey of complementary and alternative medicine use by children and adolescents attending the University Hospital of Wales

\author{
Nigel W Crawford ${ }^{1}$, Domenic R Cincotta ${ }^{1}$, Alissa Lim ${ }^{2}$ and Colin VE Powell ${ }^{* 1}$
}

Address: ${ }^{1}$ Department of General Paediatrics, University Hospital of Wales, Heath Park, Cardiff CF14 4XW, UK and ${ }^{2}$ Department of General Paediatrics, The Royal Children's Hospital, Melbourne, VIC 3052, Australia

Email: Nigel W Crawford - nwcrawford@yahoo.com.au; Domenic R Cincotta - domeniccincotta@yahoo.com.au; Alissa Lim - lima@rch.com.au; Colin VE Powell* - colin.powell@cardiffandvale.wales.nhs.uk

* Corresponding author

\section{Published: 02 May 2006}

BMC Complementary and Alternative Medicine 2006, 6:16 doi:10.1 186/1472-6882-6-16

This article is available from: http://www.biomedcentral.com/l472-6882/6/16

(C) 2006 Crawford et al; licensee BioMed Central Ltd.

This is an Open Access article distributed under the terms of the Creative Commons Attribution License (http://creativecommons.org/licenses/by/2.0), which permits unrestricted use, distribution, and reproduction in any medium, provided the original work is properly cited.
Received: 28 January 2006

Accepted: 02 May 2006

\begin{abstract}
Background: A high prevalence of CAM use has been documented worldwide in children and adolescents with chronic illnesses. Only a small number of studies, however, have been conducted in the United Kingdom. The primary aim of this study was to examine the use of CAM by children and adolescents with a wide spectrum of acute and chronic medical problems in a tertiary children's hospital in Wales.
\end{abstract}

Methods: Structured personal interviews of 100 inpatients and 400 outpatients were conducted over a 2-month period in 2004. The yearly and monthly prevalence of CAM use were assessed and divided into medicinal and non-medicinal therapies. This use was correlated with socio-demographic factors.

Results: There were 580 patients approached to attain 500 completed questionnaires. The use of at least one type of CAM in the past year was $41 \%$ (95\% Cl 37-46\%) and past month $26 \%$ (95\% Cl 23-30\%). The yearly prevalence of medicinal CAM was $38 \%$ and non-medicinal $12 \%$. The users were more likely to have parents that were tertiary educated (mother: $\mathrm{OR}=2.3,95 \% \mathrm{Cl} I .6-3.3$ ) and a higher family income (Pearson chi-square for trend $=14.3, \mathrm{p}<0.00 \mathrm{I}$ ). The most common medicinal types of CAM were nonprescribed vitamins and minerals $(23 \%)$ and herbal therapies (10\%). Aromatherapy $(5 \%)$ and reflexology (3\%) were the most prevalent non-medicinal CAMs.

None of the inpatient medical records documented CAM use in the past month. Fifty-two percent of medicinal and 38\% of non-medicinal CAM users felt their doctor did not need to know about CAM use. Sixty-six percent of CAM users did not disclose the fact to their doctor. Three percent of all participants were using herbs and prescription medicines concurrently.

Conclusion: There is a high prevalence of CAM use in our study population. Paediatricians need to ensure that they ask parents and older children about their CAM usage and advise caution with regard to potential interactions.

CAM is a rapidly expanding industry that requires further evidence-based research to provide more information on the effectiveness and safety of many CAM therapies. Statutory or self-regulation of the different segments of the industry is important. Integration of CAM with allopathic western medicine through education and better communication is slowly progressing. 


\section{Background Definition}

The use of complementary and alternative medicine (CAM) by children and adolescents is something that all health professionals involved in their care need to be aware of. CAM can be defined as, "diagnosis, treatment and/or prevention which complements mainstream medicine by contributing to a common whole, by satisfying a demand not met by orthodoxy, or by diversifying the conceptual frameworks of medicine" [1].

\section{Prevalence studies}

A high prevalence of CAM use is well documented in children with a chronic illness, for example: oncology patients 42\%, juvenile rheumatoid arthritis $70 \%$ and inflammatory bowel disease $72 \%$ [2-4]. Recent studies recorded significant usage of CAM in community paediatrics; $32 \%$ of children newly diagnosed with autism; $54 \%$ with behavioural problems and 56\% in families of children with cerebral palsy [5-7].

Reported prevalence of use in adults ranges between 9$65 \%$ [8]. Fewer studies have been conducted in children, but a systematic review in 1999 found $9-70 \%$ of them used CAM. [9] More recent CAM studies in paediatric primary care showed a reported usage of 21-33\% [10,11] and hospital based studies 12-53\%[12-14]. This study used the same methodology as a research team based at the Royal Children's Hospital in Melbourne, Australia [15]. Their study in 2002 found an overall yearly prevalence of CAM use of $51 \%$.

Few surveys have been conducted in the UK, a study of adult cancer patients in 2001 found a yearly prevalence of CAM use of $49 \%$ [16]. A paediatric study by Simpson et al. from 1996 study in the Bath area found a general paediatric outpatient prevalence of $21 \%$ [17] and in a recent Leeds study, use ranged between $12-62 \%$, in a sample which included healthy children and those with a chronic illness [18]. In a population based childhood study CAM use was $18 \%$ [19].

\section{Expenditure}

It is an expanding industry; in 2000 MacLennan et al. repeated a 1993 representative population survey in South Australia [20,21]. Extrapolation of expenditure in 2000 was AUS $\$ 2.3$ billion in Australia and US $\$ 34$ billion in the U.S. population. In Australia this represented a $62 \%$ increase and the expenditure on alternative therapies was nearly four times the public contribution to all pharmaceuticals. There is little data on CAM expenditure in the United Kingdom, in 1998 90\% of CAM provision was purchased privately with an annual out of pocket expenditure of approximately $£ 450$ million [22]. In 2003 it was determined that $£ 211$ million was spent on herbal thera- pies alone [23]. These figures are from adult based studies, making it difficult to identify expenditure on children, but it could be hypothesised that as family spending on CAM increases a proportion of this will be for use by children and adolescents.

\section{Public health}

The use of CAM in the community at large, including children, is not just a clinical or hospital based issue. There are far reaching public health implications as highlighted by the House of Lords Report into CAM [24]. The American Journal of Public Health devoted an entire issue to complementary and alternative medicine in 2002 [25]. Especially important in children is the safety of CAM therapies, their potential for interactions and regulation of the CAM industry. The efficacy of these therapies is also a major issue, which further evidence-based research needs to address.

\section{Methodological limitations}

A major limitation of the few studies conducted into CAM in children is the variable methodology and this study aims to address some of these limitations. Ernst only included only 10 of a possible 100 studies in a systematic review because of these issues [9]. Some fundamental problems with study design included the fact that most used a self-administered questionnaire, which has significant limitations, including problems of confusion of the overall meaning of questions and misinterpretation of individual terms or concepts that cannot be clarified. This is particularly important in the CAM field where definition and clarification is so important. Self-administered questionnaires may often be incomplete and have a poorer response rate than an interview administered questionnaire. The size of previous studies has also been variable, as has the country survey's have been conducted in. This combined with a variable definition of CAM makes direct comparisons difficult. The time frame of CAM use is also often not clear, with many using 'lifetime prevalence', that is CAM use at any point in the past. This is prone to recall bias. A discussion on adverse effects was not mentioned in $70 \%$ of the papers reviewed and $90 \%$ of did not clarify the cost of these therapies. The review was conducted in 1998, but many of the problems outlined above still exist, with surveys on CAM use in children often being self-administered questionnaires and include lifetime prevalences.

\section{Aims}

The primary aim was to examine the use of CAM by children and adolescents in a tertiary children's hospital in Wales. This included those with acute and chronic illnesses. Secondary aims include: 1 . Investigate association of CAM usage with socio-demographic factors, 2. Ascertain the frequency of CAM use, its cost and perceived help- 
fulness, 3. Explore patients'/parents' knowledge regarding the risks of side effects from CAM and their possible interactions with other therapies, 4 . Identify whether CAM use is discussed with medical practitioners and whether inpatient medical records showed any evidence of appropriate documentation and 5. Examine the public health implications of CAM use

\section{Methods}

A cross-sectional survey of the use of CAM by children and adolescents was undertaken from January to February 2004 at the University Hospital of Wales (UHW), Cardiff. This is a tertiary paediatric centre with approximately 10,000 inpatients and 6,500 outpatients seen per year (Allaway J, personal communication, 2005). The questionnaire was based on that used in an identical study at the Royal Children's Hospital, Melbourne, Australia [15].

The sample population of 500 participants were divided into 100 inpatients and 400 outpatients. The age range was between $0-18$ years. The outpatients were also in groups of 100, namely: endocrinology, general paediatrics, gastroenterology and respiratory. These groups were chosen to produce a broad cross-section of the tertiary hospital population. The sample was obtained by interviewing consecutive inpatient admissions and children attending the relevant outpatient clinics over the study period. None of the paediatricians caring for children at UHW were practitioners of any form of CAM.

Data were collected in a structured interview-administered questionnaire with the patient and/or parents/ guardian. It took approximately 10-15 minutes to complete. There were four interviewers involved in the study (NC, DC, AR \& DW). Three of interviewers were paediatricians in training and the fourth (DW) a pre-registration pharmacist. All were calibrated prior to commencement of the study, by discussing as a group questionnaire administration and recording of data. The questionnaire had been piloted in Melbourne and some of the difficulties in administering the questionnaire were discussed with their research team. The questions were predominantly of a closed nature with multiple categories, including areas for comments. The interviewers were not involved in the medical treatment of the patients and did not enter into discussions regarding their personal opinions about CAM. Any specific questions regarding therapies were directed to their treating medical practitioner.

Exclusion criteria included insufficient knowledge of English and those children/adolescents admitted to intensive care. Written consent was obtained prior to commencing the interview. All patients/parents were given an information sheet. The South East Wales Local Research and Eth- ics Committee and the Research and Development committee at UHW approved the study.

\section{Definition}

The type of CAM was divided into seven medicinal (naturopathic, herbal, homeopathic, Traditional Chinese medicine, health products, dietary and food supplements or non-prescribed vitamins and minerals) and thirteen non-medicinal (chiropractic, naturopathy, Traditional Chinese therapies, acupuncture, aromatherapy, iridology, therapeutic massage, reflexology, Buteyko breathing, kinesiology, reiki, hypnosis, special exercises or modified diet) therapies. There was also a free text area for CAM therapies not included on the list. Use of these therapies in the last year and past month was clarified. Non-prescribed vitamins and minerals were included as a CAM because a medical practitioner is not monitoring their use, despite them being taken as a medicine with therapeutic intent.

\section{Statistical considerations}

In determining the sample size a literature review was performed to determine the expected frequency of CAM usage. This was estimated to range between $10-70 \%$. [9] A sample size of 100 for each group (500 subjects in total) will estimate any proportion to within $+/-10 \%$, or better, with $95 \%$ confidence. This sample size is also identical to that used in the in Melbourne study [15]. The data was entered into a Microsoft Excel $^{\circ}$ database and analysed using SPSS version $11.0^{\circ}$. Initial univariate analyses compared users and non-users of CAM. Proportions were compared using a Pearson chi-square test, with point estimate and 95\% confidence intervals determined and a 'p value' of $<0.05$ considered statistically significant.

The data entry was checked by manually reviewing a computer generated random 5 percent of the data set at completion of the study. The stability of the questionnaire was reviewed by re-conducting the interview in a random 5 percent of respondents. This was done by telephone, 4-6 weeks after the initial interview. The interviewers were also compared, looking at any differences in CAM disclosure. Data has been collected and presented in an anonymous manner. All master copies of subject lists and questionnaires were retained securely within the Department of Paediatrics, UHW.

\section{Results}

Five hundred and eighty patients were approached to complete 500 questionnaires. Five were excluded because of insufficient English language skills and 39 were missed because they left before being seen in busy clinics. Ten had already been seen in previous clinics or as inpatients and were therefore not re-interviewed. There were 23 who refused or did not fully complete the survey and 3 who did 
not have a legal guardian present. The interview was conducted with the index case (adolescent) in $7 \%$ of cases and their mother in $75 \%$, father $17 \%$ and other guardian in $1 \%$.

The study population of 500 interviewed was $52 \%$ male, with a mean age of 8 years (standard deviation 5.1 years) and a median of 7.8 years (range: 1 month to 19 years). The family income was greater than $£ 20,000$ for $52 \%$ of those studied. Tertiary education had been gained by $47 \%$ of mothers and $48 \%$ of fathers. Sixteen percent of families had private health cover that included cover of the index case.

Table 1 . outlines 1 -yearly CAM usage. The yearly prevalence of using at least one CAM was 206 out of 500 or $41 \%$. The point prevalence of all CAM use in the last month was $26 \%$. The prevalence of CAM use were very similar in the inpatients and the four different outpatient groups, except for being possibly slightly higher in the respiratory group (49\%).

Table 2 outlines the socio-demographic factors associated with CAM use. Those using CAM had a higher family income and parental tertiary education. There were no differences in CAM use with regards to gender, age, number of children in the household or private health insurance.

The most commonly used types of CAM are outlined in Figure 1. The most frequently used medicinal CAM were non-prescribed vitamins and minerals and herbal therapies. In non-medicinal CAM group aromatherapy and reflexology were the most commonly used.

The use of prescription medications in the last month was $73 \%$ (358/493). The types of medications used were classified into the listed groups in Table 3. A total of $22 \%$ $(108 / 493)$ used medications from more than one group. Five percent of participants had used herbal medicines in

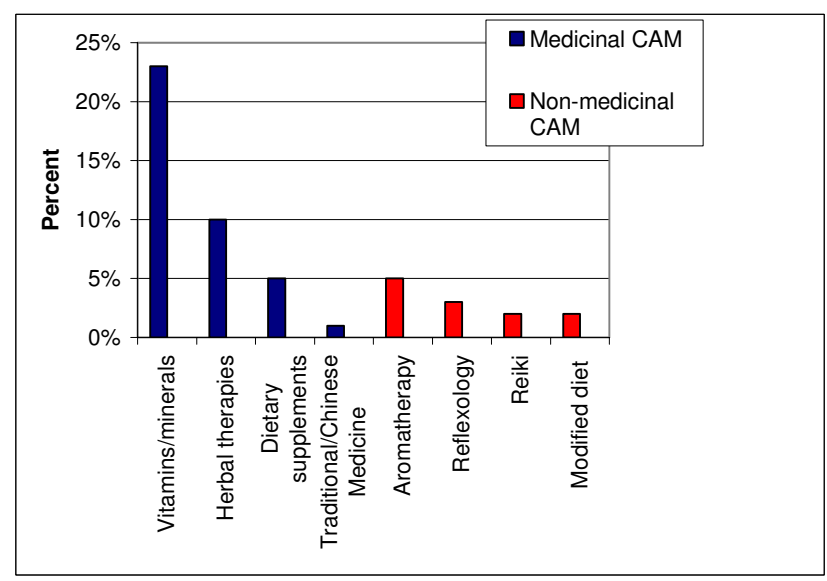

\section{Figure I}

Most common types of CAM used- medicinal and nonmedicinal (percentage of total participants).

the last month and of those $68 \%$ (17/25) were also using a prescription medication. Thus $3 \%$ of participants overall were using herbs and prescription medications concurrently. Only 13\% (32/256) of respondents knew there was the potential for interactions and of those, 56\% (18/32) could actually specify one. Of those using CAM 5\% (9/ 182) had experienced side effects. All of the side effects described were of a minor nature. The knowledge of any potential side effects of CAM was 15\% (73/500) and $82 \%$ (60/73) of those could name one. None of the 23 inpatients using CAM in the last month had this documented in medical or nursing notes.

Expenditure is depicted in Figure 2. There is a trend towards higher expenditure in non-medicinal CAM, which had a higher median cost ( $£ 5-20$ per month) than medicinal CAM ( $£ 1-4$ per month).

CAM was self- initiated (parent/participant/family/ friend) in $74 \%$, with much lower initiation/recommenda-

Table I: I-year Prevalence of Complementary and Alternative Medicine (CAM) Use

\begin{tabular}{lcc}
\hline Group & Prevalence (\%) & 95\% Confidence Interval (\%) \\
\hline Any CAM Use (overall) & 41 & $37-46$ \\
Medicinal CAM & 38 & $34-42$ \\
Non-medicinal CAM & 12 & $9-14$ \\
Both medicinal and non-medicinal CAM & 8 & $6-10$ \\
Excluding vitamins and minerals & 25 & $21-29$ \\
CAM $>$ I= 3 times (of total participants) & 36 & $32-41$ \\
Patient Group & & $30-49$ \\
Inpatients CAM use & 39 & $30-49$ \\
Endocrine CAM Use & 39 & $28-47$ \\
General Paediatric CAM Use & 37 & $33-52$ \\
Gastroenterology CAM Use & 42 & $39-59$ \\
Respiratory CAM Use & 49 &
\end{tabular}


Table 2: Socio-demographic factors associated with CAM use

\begin{tabular}{|c|c|c|c|c|}
\hline Variable & CAM users/Total & Percent \% & $\begin{array}{l}\text { Pearson chi-square } \\
\text { for trend }(\mathrm{df}=\mathrm{I})\end{array}$ & p value \\
\hline \multicolumn{5}{|l|}{ Demographics } \\
\hline \multicolumn{5}{|l|}{ Age (yr) } \\
\hline$<2$ & $33 / 74$ & 45 & & \\
\hline $2-4$ & $36 / 97$ & 37 & & \\
\hline $3-8$ & $48 / 103$ & 47 & & \\
\hline $9-11$ & $28 / 89$ & 31 & & \\
\hline$>12$ & $61 / 137$ & 46 & 0.27 & 0.60 \\
\hline \multicolumn{5}{|c|}{ Household Income $(\ell)$} \\
\hline$<6000$ & $8 / 37$ & 22 & & \\
\hline $6001-12000$ & $16 / 53$ & 30 & & \\
\hline$|200|-20000$ & $45 / 109$ & 41 & & \\
\hline $20001-30000$ & $35 / 94$ & 37 & & \\
\hline$>30000$ & $83 / 159$ & 52 & 14.30 & $<0.001$ \\
\hline \multicolumn{5}{|c|}{ No. of children in household } \\
\hline One & $49 / 120$ & 41 & & \\
\hline Two & $89 / 205$ & 43 & & \\
\hline Three & $41 / 101$ & 41 & & \\
\hline$>$ Three & $25 / 69$ & 36 & 0.44 & 0.51 \\
\hline Variable & CAM users/Total & Percent\% & Odds Ratio (95\% C.I.) & $p$ value \\
\hline \multicolumn{5}{|l|}{ Sex } \\
\hline Male & $113 / 259$ & 44 & c & \\
\hline Female & $93 / 241$ & 39 & $0.8(0.6-1.1)$ & 0.25 \\
\hline \multicolumn{5}{|c|}{ Country of birth (child) } \\
\hline UK & $201 / 485$ & 41 & c & \\
\hline Overseas & $4 / 13$ & 31 & $0.6(0.2-2.1)$ & 0.44 \\
\hline \multicolumn{5}{|c|}{ Country of birth (mother) } \\
\hline UK & $186 / 455$ & 41 & c & \\
\hline Overseas & $18 / 42$ & 43 & I.I $(0.6-2.1)$ & 0.80 \\
\hline \multicolumn{5}{|c|}{ Country of birth (father) } \\
\hline UK & $179 / 440$ & 41 & c & \\
\hline Overseas & $24 / 54$ & 44 & $1.2(0.7-2.1)$ & 0.60 \\
\hline \multicolumn{5}{|c|}{ Post secondary education (mother) } \\
\hline No & $84 / 260$ & 32 & c & \\
\hline Yes & $|20 / 23|$ & 52 & $2.3(1.6-3.3)$ & $<0.001$ \\
\hline \multicolumn{5}{|c|}{ Post secondary education (father) } \\
\hline No & $92 / 249$ & 37 & c & \\
\hline Yes & $109 / 234$ & 47 & $1.5(1.0-2.1)$ & 0.03 \\
\hline \multicolumn{5}{|l|}{ Private Insurance } \\
\hline No & $|70 / 4| 8$ & 41 & c & \\
\hline Yes & $34 / 77$ & 44 & $1.2(0.7-1.9)$ & 0.57 \\
\hline
\end{tabular}

$c=$ comparative group

tion by doctors (6\%) or CAM practitioners (14\%), At least one CAM was perceived as helpful by 57\% (117/206) of CAM users. The use of CAM was not disclosed to the medical practitioner in 66\% (135/206)of cases. 52\%(97/185) medicinal and 38\% medicinal CAM as safe (19\%), natural (9\%) and available over the counter (7\%). Quotes included: "Doctors don't have the time" or are "Not inter- ested", "I wanted to tell the doctor but feel that they don't want to hear", "doctors not bothered by colic", or the "doctor is ignorant so would not be interested".

The four interviewers were compared with regards to disclosure of CAM use in the past year as shown in Table 4. The random data check revealed a maximum error rate of 
Table 3: Use of prescription drugs in the past month. *Based on table by Madsen et al.[14] [N = 493]

\begin{tabular}{lll}
\hline & $\mathrm{n}$ & $\%$ \\
\hline No drug use & 135 & 27 \\
Drugs against cardiac disease & 8 & 2 \\
Drugs against CNS disease (e.g. anticonvulsants) & 22 & 5 \\
Anti-neoplastic drugs (prednisolone, immunosuppressive & 36 & 7 \\
drugs, folic acid) & & \\
Drugs against GI disease & 71 & 14 \\
Insulin or other hormones & 71 & 14 \\
Antibiotics and other systemic drugs against infectious & 99 & 20 \\
diseases & 103 & 21 \\
Drugs for asthma, eczema, allergy & 77 & 16 \\
Other: Over the counter (OTC), paracetamol nutritional \\
supplements/vitamins on doctors prescription
\end{tabular}

$0.7 \%$ (95\%CI $0.4-1.3 \%)$. The stability testing of the questionnaire showed a $3.3 \%$ (95\% CI $2.5-4.4 \%)$ difference in responses when the survey was re-conducted over the telephone.

\section{Discussion Prevalence}

Our results with a yearly prevalence of $41 \%$ (95\% confidence interval (CI) $37-46 \%$ ) is in the upper range compared with studies worldwide [9]. Our general paediatric subgroup used $37 \%$ (95\%CI 28-47\%), which is higher than the general paediatric outpatient UK study in 1996 [17]. This may be a true increase in CAM use over that time, but confounders include; differences in the two outpatient populations, the definition of CAM used or the fact that our study was interview led, rather than a selfadministered questionnaire, which may underestimate use. There was no statistical difference in the prevalence amongst the inpatient and outpatient groups with overlap of the $95 \%$ confidence intervals (Table 1). All of the four outpatients included patients with chronic illnesses and the high number of cystic fibrosis patients in the respiratory outpatients may partially explain their slightly higher prevalence. The prevalence in Cardiff is significantly lower the prevalence found in the Melbourne study (51\%, 95\% CI 47-56\%) [15]. The reasons for this difference have been explored in a separate comparative analysis between the two tertiary centres [26].

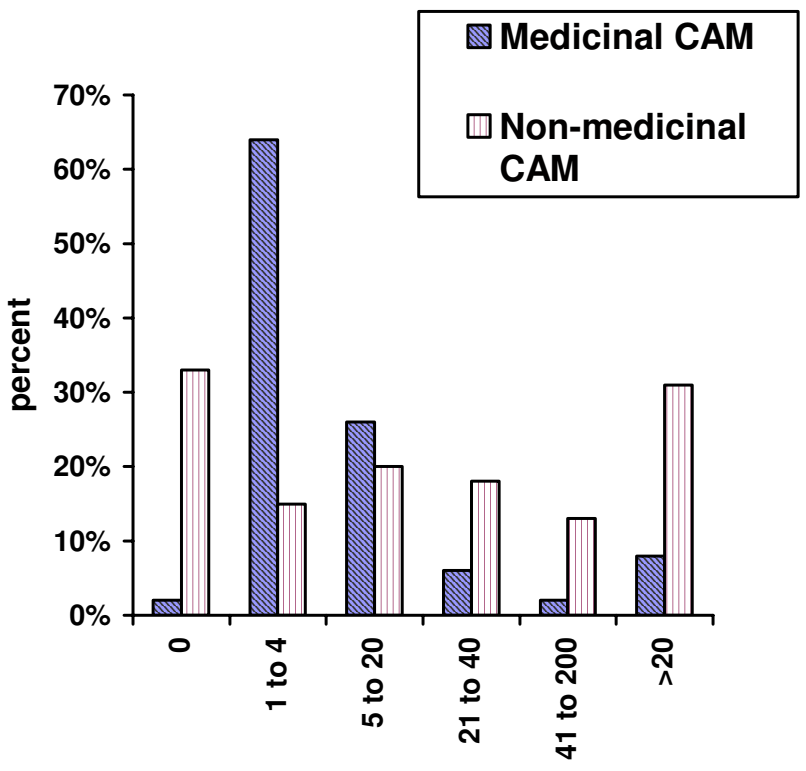

$£$ per month

Figure 2

Expenditure on CAM ( $\_$per month).

\section{Socio-demographic factors}

Socio-demographic factors associated with CAM use were parental tertiary education and high income. This supports the view that CAM is associated with higher socioeconomic status $[12,14]$. Higher levels of education may lead to exposure to these therapies, especially given their high profile in the media. The lack of other socio-demographic factors implicated in CAM use from our study supports many of the previous surveys $[11,13,27]$.

\section{Cost}

Nearly two-thirds of medicinal CAM cost less than $£ 5$ per month, with about one-third spent nothing per month. This supports the assertion that CAM may not be as expensive as is commonly believed, as concluded by a large Canadian study which found that CAM was less than CAN $\$ 20$ in $37 \%$ of cases and more than CAN\$60 in only

Table 4: CAM use disclosure by interviewer

\begin{tabular}{|c|c|c|c|}
\hline Interviewer & Occupation & $\begin{array}{c}\text { Number of CAM users/Total } \\
\text { number interviewed }\end{array}$ & $\begin{array}{l}\text { Percentage ( } 95 \% \text { confidence } \\
\text { interval) }\end{array}$ \\
\hline NC & Paediatric Specialist Registrar & 73 out of 210 & $35 \%(29-41 \%)$ \\
\hline $\mathrm{DC}$ & Paediatric Specialist Registrar & 50 out of 127 & $39 \%(31-48 \%)$ \\
\hline AR & Paediatric Senior House Officer & 46 out of 100 & $46 \%(37-56 \%)$ \\
\hline DW & Pharmacy student & 37 out of 63 & $63 \%(46-70 \%)$ \\
\hline
\end{tabular}


$6 \%$ [27]. A BBC commissioned survey in 1999 of CAM use amongst adults in the United Kingdom approximated CAM expenditure of $£ 14$ per month with about one-third spending less than $£ 5$ per month [28]. Non-medicinal CAM tended to be more costly as seen in this study, with about one-third spending more than $£ 20$ per month and $13 \%$ spending more than $£ 40$. This may limit their availability and therefore prevalence, which was significantly less than medicinal forms of CAM (12\%. versus $41 \%)$. Of note some non-medicinal therapies were 'free' because treatments such as therapeutic massage or reiki were provided at no cost by friends or relatives.

\section{Disclosure}

Disclosure of CAM use to medical practitioners is important if the issue is to be discussed and any potential interactions or adverse effects detected. In our study $66 \%$ did not disclose CAM usage to their doctor, which is similar to previous studies $[15,18,29]$. Reasons for lack of disclosure may reflect a perceived lack of acceptance by the physician. It is important part of doctor-patient communication that issues such as CAM is discussed in a nonjudgmental and open manner. The "don't ask, don't tell" status quo, [29] is also reflected in the fact that there was no documentation of recent CAM use in the inpatient notes. Poor communication is supported by other studies, which found few doctors (16\%) ask about CAM use [30].

In a study of paediatricians and nurses attitudes to CAM, many using CAM themselves, but only $40 \%$ actually asked about CAM [31]. The main reason given for not discussing these therapies was a lack of confidence to do so because of minimal education about these therapies and the limited safety and efficacy data available.

\section{Efficacy and perceptions}

A review of 19 surveys between 1982 to 1995, looking into the referral patterns of physicians to CAM practitioners, highlighted the fact that decisions need to be based on efficacy studies, rather than "regional economics and cultural norms", and "somewhere between over enthusiastic belief and stubborn disbelief is a balanced perspective that will help patients and advance medical science" [32]. The perception of parents and adolescents of doctors as not being interested was commonly found in this study, with quotes including: "they were not interested", "did not have the time" or "wanted to tell the doctor but feel that they don't want to hear".

\section{Integrative medicine}

Integrative medicine refers to "looking at a broad range of therapies and considering those that have the best evidence of safety and effectiveness in the context of holistic care". [33] It has been strongly supported by The Prince of Wales's Foundation for Integrated Health [34] and is becoming an important component of medical education. Cohen provides a practical example of integrative care, focusing on the chronically ill, "as many of these patients could benefit from the services of CAM practitioners... and as evidence emerges that some CAM are effective then it becomes ethically impossible for the medical profession to ignore them". [35] Studies have found that CAM practitioners are keen on integration. [36]

\section{Safety}

One of the major concerns for medical practitioners regarding CAM use is safety. Despite popular belief, CAM is not always "natural" and "safe" or free of side effects, and there are many case reports of adverse events in children. These include: death, neurological disability, organ failure and organ puncture[37]. Possible interactions between medicinal CAM, particularly herbal remedies and prescription medications, is well documented [38]. When questioned the majority (87\%) of adolescents or parents in this study could not name a potential interaction. It was determined that there was a $3 \%$ risk of a participant in the study concurrently taking a herb and prescription medication. This is quite a small number in our hospital-based population and may mean that the interaction potential is less than previously believed. All ingested therapies, however, have the potential to interact so communication and reporting of interactions remains very important. Up-to-date information about CAM is becoming more available with pharmacists, local drug advisory services and some Internet resources useful $[39,40]$.

\section{Evidence-based medicine}

Funding is a major issue for producing quality evidencebased research into CAM as resources are still allocated predominantly through traditional biomedical channels and in 1996 only $0.08 \%$ of funding in medical sciences was going into CAM [41]. As stated by Ernst; "The scientific establishment criticises the paucity of data and weakness of CAM hypotheses with one breath and with their next breath they withhold the money that would be essential for changing this situation" [42].

\section{Regulation}

Following the House of Lords Science and Technology Committee report on CAM in 2000, there was a push for some CAM practitioners such as Osteopaths and Chiropractors to follow the medical model of statutory regulation as seen with the General Medical Council [24]. Alternatives to statutory regulation are self regulation, with development of national standards regarding training and competence. Welsh et al. looked in depth at the tensions and difficulties in CAM practitioners seeking selfregulation [43]. The Prince of Wales's Foundation for Inte- 
grated Health has also played an important role in this area [34].

All professions are prone to rogue practitioners, such as those outlined in the study of Traditional Chinese therapists treating atopic eczema with topical remedies that were shown on analysis to contain high levels of potentially hazardous steroids [44]. In these situations it is important that the public sees effective and visible disciplinary procedures.

\section{Limitations of this study}

There were a number of potential areas of bias in this study, namely: 1. Questionnaire 2. Interviewer, 3. Interviewee, 4. Sampling, 5. Language bias. The questionnaire itself may have produce bias towards the listed agents as it is not possible to include all CAM therapies and there was a free text area. This was minimised by extensive review of the literature and including 7 medicinal and 13 nonmedicinal therapies in the interview led questionnaire. Of note 5 of the 20 therapies accounted for the majority of CAM use, with some CAM only being used by less than $2 \%$ of the study population.

Despite calibrating the interviewers with a view to obtaining consistent responses, it remains possible that inconsistencies in asking questions and recording answers occurred The interviewers [NC, DC, AH, DR] had variable amounts of CAM disclosed (Table 4) and in particular CAM use was much higher $(63 \%)$ in the surveys conducted by DW. He was a pharmacy student whilst the other three interviewers were paediatric trainees. All interviewers were similarly attired, with no identifying features. DW interviewed only a small proportion of participants $(13 \%)$.and none of the inpatient subgroup. DW may have had higher CAM disclosure because as the only pharmacist amongst the interviewers he may have been better at gaining information about medication use and CAM. Alternatively there could have been some potential bias in the parents/patients perceptions of the different interviewers, thus affecting disclosure. In particular, the role of the three doctors as interviewers may have led participants to feel that they would not approve of CAM use. This would produce an under-estimate of CAM use in our population. The fact that the interviews were conducted in a busy outpatient clinic and on the inpatient wards may have inhibited disclosure of CAM use in some cases.

Different responses may also be obtained when interviewing the patient or either parent about CAM. The knowledge and opinions regarding CAM may differ within the family. The mother $(75 \%)$ was the person most commonly interviewed in the survey. The prevalence may be under-estimated in cases where a guardian with less knowledge about the child completed the questionnaire. This study asked about CAM use in the past year, which is prone to recall bias, as participants may find it difficult to remember exactly what therapies were used. Repeating the questionnaire over the phone showed that it had stability with only a 3.3\% difference in responses. There was, however, no differentiation made between positive or negative differences and individuals may have started or stopped taking CAM in the two months between the two surveys. It is also possible that respondents were more educated about CAM after becoming involved in the study, affecting the responses in the repeat questionnaire.

A representative sample is difficult to obtain, but by approaching consecutive inpatient admissions and outpatient presentations, the potential for sampling bias was minimised. Only 80 cases were excluded and 10 of those were because they had been interviewed previously. Information was not obtained to directly compare the demographics or other details of the 80 excluded cases from the 500 respondents.

This study excluded a small number of subjects ( 5 in total) who had insufficient knowledge of English, leading to language bias. Whilst this is a small number overall, it may be expected from the literature and on general principles that this group is more likely to use CAM. Cost was a factor as this study was not funded and there were insufficient resources to provide questionnaires in different languages or provide independent interpreters. This study was also designed with the aim of doing a direct comparison of CAM use between Cardiff and Melbourne, so their methodology was replicated, including exclusion of those with insufficient English language skills. Whilst this strengthens the comparability of data it highlights the need for further research into specific ethnic groups and CAM subtypes utilised by them.

\section{Applicability of the study}

As outlined previously methodologies used in CAM surveys vary, reducing the comparability of studies and hence the applicability of our study elsewhere. The study population was a tertiary paediatric group based at one location, comprising children with acute and chronic illnesses. The results whilst not applicable to the general population, may apply to other tertiary paediatric centres with similar demographics and case-mix. Well-conducted population based studies are require to ascertain the overall use of these therapies in children.

\section{Conclusion}

This study confirms a high prevalence of use in our tertiary paediatric population. CAM cannot be ignored and medical practitioners need to be better educated about these therapies. As stated by Coulter, "CAM is here to stay and 
will continue to present challenges for conventional medicine of how to respond"[45]. Paediatricians need to specifically ask about CAM use and document this appropriately. It should be discussed with patients in an open, non-judgemental way. In particular patients and medical practitioners should be aware of potential interactions and liaise with their pharmacy or drug advisory department if required. This will help patients and their parents make more informed, safe choices. Further evidence-based studies are required to provide more information on the effectiveness and safety of many CAM therapies [46]. The public health implications of CAM are far reaching and include regulation of the industry and protection of the public through appropriate safety and monitoring measures. Integrative medicine is slowly progressing bringing together western allopathic medicine and CAM therapists through improved communication and education.

\section{Competing interests}

The author(s) declare that they have no competing interests.

\section{Authors' contributions}

$\mathrm{NC}$ was an interviewer and co-author of the drafted manuscript. DC was also an interviewer and co-author of the drafted manuscript. AL provided background information and the questionnaire on which this study was based [15]. CP conceived of the study and was supervisor of the project. All authors read and approved the final manuscript.

\section{Acknowledgements}

- Associate Professor Noel E Cranswick, Dr Sue Skull and Professor Mike South, Royal Children's Hospital, Melbourne Australia. All members of the Melbourne research team who developed the CAM questionnaire and methodology used in this study.

- Professor Robert Newcombe, Department of Epidemiology and Public Health, Cardiff University as supervisor of NC's MPH dissertation (Cardiff University) and for statistical assistance

Thanks to:

- Dr Ajay Ready (AR) \& Dean Whittle (DW) for interviewing participants.

- Ms Jenny Cope for designing the database and data entry and Mrs Janine Cincotta for assistance with data entry.

\section{References}

I. Ernst E, Resch KL, Mills S, Hill R, Mitchell A, Willoughby M: Complementary medicine- a definition. Br / Gen Pract 1995, 45:506.

2. Fernandez CV, Strutzer CA, MacWilliam L, Fryer C: Alternativeand complementary medicine use in pediatric oncologypatients in British Columbia; prevalence and reasons for useand nonuse. J Clin Oncol I 998, I 6(4): I 279-1286.

3. Southwood TR, Malleson PN, Roberts-Thompson PJ, Mahy M: Unconventional therapies used for patients with juvenile arthritis. Pediatrics 1990, 85:|50-154.
4. Day AS, Whitten KE, Bohane TD: Use of complementary andalternative medicines by children and adolescents withinflammatory bowel disease. J Paediatr Child Health 2004, 40:68I-684.

5. Levy SE, Mandell DS, Merhar S, Ittenbach RF, Pinto-Martin JA: Use of complementary and alternative medicine amongchildren recently diagnosed with autistic spectrum disorde. J Dev Behav Paediatr 2003, 24(6):4I 8-23.

6. Chan E, Rappaport LA, Kemper KJ: Complementary andalternative therapies in childhood attention and hyperactivity problems. J Dev Behav Paediatr 2003, 24(I):4-8.

7. Hurvitz EA, Leonard C, Ayyangar R, Nelson VS: Complementaryand alternative medicine use in families of children withcerebral palsy. Dev Med Child Neurol 2003, 45(6):364-70.

8. Ernst E: Prevalence of the use of complementary/alternativemedicine: a systematic review. Bull World Health Organ 2000 , 78(2):252-257.

9. Ernst E: Prevalence of complementary/alternative medicine forchildren: a systematic review. Eur J Paediatr 1999, I58(I):7-II.

10. Loman DG: The use of complementary and alternative healthcare practices among children. J Paed Health Care 2003, I 7(2):58-63.

II. Ottolini MC, Hamburger EK, Loprieato JO, Coleman RH, Sachs HC, Madden R: Complementary and alternative medicine useamong children in the Washington DC area. Ambul Paediatr 200I, I(2): I 22- I 25.

12. Fong DS, Fong LS: Usage of complementary medicine among children. Aus Fam Physician 2002, 3 I (4):388-39l.

13. Armishaw J, Grant CC: Use of complementary treatment bythose hospitalised with acute illness. Arch Dis Child 1999, 8I:133-137.

14. Madsen H, Andersen S, Nielsen RG, Dolmer BS, Host A, Damkier A: Use of complementary/alternative medicine amongpaediatric patients. Eur J Paediatr 2003, I 62:334-34I.

15. Lim A, Cranswick N, Skull S, South M: Survey of complementaryand alternative medicine use at a tertiary children's hospital. J Paediatr Child Health 2005, 4 I (8):424-427.

16. Harris P, Finlay IG, Cook A, Thomas KJ, Hood K: Complementary and alternative medicine use by patients with cancer in Wales: a cross sectional survey. Complement Ther Med 2003, I I :249-253.

17. Simpson NP, Pearce A, Finlay F, Lenton S: The use ofcomplementary medicine in paediatric outpatient clinics. Ambulatory Child Health 1998, 3:351-356

18. McCann L, Newell S: Survey of paediatric complementary andalternative medicine use in children in health and chronic illness. Arch Dis Child 2006, 91 : I73-174.

19. Simpson N, Roman K: Complementary medicine use in children:extent and reasons. A population-based study. $\mathrm{Br} J \mathrm{Gen}$ Pract 2001, $51: 914-916$.

20. MacLennan $\mathrm{AH}$, Wilson $\mathrm{DH}$, Taylor AW: Prevalence and cost ofalternative medicine in Australia. Lancet 1996, 347:569-73.

21. MacLennan AH, Wilson DH, Taylor AW: The escalating cost andprevalence of alternative medicine. Prev Med 2002, 35: I66-I73.

22. Thomas KJ, Nicholl JP, Coleman P: Use and expenditure on complementary medicine in England:a population based survey. Complement Ther Med 2001, 9:2-II.

23. De Smet PAGM: Herbal Medicine in Europe - RelaxingRegulatory Standards. NEJM 2005, 352: I I76-I I 78.

24. House of Lords, Select Committee on Science and Technology-Sixth Report: Complementary and Alternative Medicine. In Session 1999-2000: HL paper 123 The Stationary Office, London.

25. American Journal of Public Health: 'Complementary and Alternative Medicine'. 2002, 92( I 0):.

26. Cincotta DR, Crawford NW, Lim A, Cranswick NE, Skull S, South M, Powell CVE: Comparison of complementary and alternativemedicine use: reasons and motivations between two tertiarychildren's hospitals. Arch Dis Child 2006, 9 I:I I53-I 58.

27. Spigelblatt L, Laine-Ammara G, Pless IB, Guyver A: The use ofalternative medicine by children. Pediatrics 1994, 94(6):8 I I-4.

28. Ernst E, White A: The BBC Survey of Complementary MedicineUse in the UK. Complement Ther Med 2000, 8:32-6.

29. Eisenberg DM, Davis RB, Ettner SL, Appel MS, Wilkey S, Van Rompay $M$ : Trends in alternative medicine use in the UnitedStates, 1990-1997: results of a follow-up national survey. JAMA I998, 280( I 8): I569-75. 
30. Sibinga EM, Ottolini MC, Duggan AK, Wison MH: Parent- Pediatrician Communication about Complementary and Alternative Medicine Use for Children. Clin Pediatr 2004, 43:367-73.

31. Fearon J: Complementary therapies: knowledge and attitudesof health professionals. Pediatri Nurs 2003, I5(6):30-35.

32. Astin J, Marie A, Pelletier KR, Hansen E, Haskell WL: A review of the incorporation of complementary and alternative medicineby mainstream physicians. Arch Int Med 1998, I 58:2303-I0.

33. Gaudet $\mathrm{T}$ : Integrative medicine: the evolution to a newapproach to medicine and medical education. Integrat Med 1998, 1:67-73.

34. Prince of Wales's Foundation for Integrated Health [http:// www.fihealth.org.uk/]. (last accessed 22nd May 2005)

35. Cohen MM: CAM practitioners and "regular" doctors: isintegration possible? Med J Austral 2004, 1 80( I 2):645-6.

36. Barrett B, Marchand L, Scheder J, Appelbaum D, Plane MB, Blustein J: What complementary and alternative medicinepractitioners say about health and health care. Ann Fam Med 2004, 2(3):253-9.

37. Ernst E: Serious adverse effects from unconventional therapiesfor children and adolescents: a systematic review of recent evidence. Eur J Paed 2003, 162:72-80.

38. Fugh-Berman A: Herb-drug interactions. Lancet 2000, 355:।34-8.

39. Natural Database [http://www.naturaldatabase.com]. (last accessed 22nd May 2005)

40. Memorial Sloan-Kettering Cancer Centre [http:// www.mskcc.org/mskcc/html// I570.cfm]. (last accessed the 22nd May 2005)

4I. Ernst E: Only $\mathbf{0 . 0 8 \%}$ of funding for research in NHS goes to complementary medicine. Br Med J 1996, 313:882.

42. Ernst E: The "improbability" of complementary and alternative medicine. Arch Int Med 2004, I 64(8):9|4-5.

43. Welsh S, Kelner M, Wellman B, Boon H, Moving forward?: Complementary and alternative practitioners seeking self regulation. Sociol Health IIIn 2004, 26(2):2 I6-4I.

44. Ramsay HM, Goddard W, Gill S, Moss C: Herbal creams used foratopic eczema in Birmingham, UK illegally contain potent corticosteroids. Arch Dis Child 2003, 88( (12): 1056-7.

45. Coulter ID, Willis EM: The rise and rise of complementary andalternative medicine: a sociological perspective. Med J Austral 2004, I 80(II):587-589.

46. Ernst E: Complementary and alternative medicine for children: agood or a bad thing? Arch Dis Child 2006, 91 :96-97.

\section{Pre-publication history}

The pre-publication history for this paper can be accessed here:

http://www.biomedcentral.com/1472-6882/6/16/prepub
Publish with Bio Med Central and every scientist can read your work free of charge

"BioMed Central will be the most significant development for disseminating the results of biomedical research in our lifetime. "

Sir Paul Nurse, Cancer Research UK

Your research papers will be:

- available free of charge to the entire biomedical community

- peer reviewed and published immediately upon acceptance

- cited in PubMed and archived on PubMed Central

- yours - you keep the copyright
BioMedcentral 